\title{
Occurrence of Salmonella sp in Laying Hens
}

Author(s)

Gama NM SQ ${ }^{1}$

Berchieri Jr A ${ }^{2}$

Fernandes $\mathrm{SA}^{3}$

1-Instituto Biológico - Unidade de Pesquisa e Desenvolvimento de Bastos

2 - FCAV/ UNESP, Jaboticabal - SP

3-Instituto Adolfo Lutz, São Pulo - SP

\section{Mail Address}

Nilce M aria Soares Q. Gama

Unidade de Pesquisa e Desenvolvimento de Bastos

Av. Gaspar Ricardo, 1700

17.690.000 - Bastos - SP - Brasil

E-mail: laboratório@only.com.br

Keywords

eggs, feces, laying hens, Salmonella

\section{Acknowledgments}

The authors would like to thank CNPq for financial support and Elizabeth Guastalli, Helena Yajima, Milta Gonçalves, Rogério Fernandes (Instituto Biológico), Antônio José dos Santos and Aparecida Rodrigues da Silva (UNESP) for laboratory assistance.
Arrived: october 2001

Approved: september 2002

\section{ABSTRACT}

This study was carried out to investigate the presence of Salmonella $\mathrm{sp}$ in flocks of white laying hens. In different farms, the transport boxes of twelve flocks were inspected at arrival for the presence of Salmonella. Four positive ( $A, B, L$ and $M)$ and one negative (I) flocks were monitored at each four weeks using bacteriological examination of cecal fresh feces up to 52 weeks. Birds were also evaluated at 52 weeks, when 500 eggs were taken randomly, and at 76 weeks, after forced molt. Salmonella enterica serovar Enteritidis and $\mathrm{S}$. enterica rough strain were isolated from the transport boxes of the four positive flocks (flocks $A, B, L$ and $M$ ). Salmonella sp was not isolated from the transport boxes or from the feces after 76 weeks-old in flock I. Salmonella sp was isolated in the $1^{\text {st }}$, $11^{\text {th }}, 34^{\text {th }}, 42^{\text {td }}$ and $76^{\text {th }}$ weeks from flock $A$; in the $1^{\text {st }}, 4^{\text {th }}, 11^{\text {th }}$ and $76^{\text {th }}$ weeks from flock $B$; in the first week and in the $17^{\text {th }}$ to $52^{\text {nd }}$ weeks from flock L; and in the $1^{\text {st }}$ and $76^{\text {th }}$ weeks from flock M. S. Enteritidis, S. enterica rough strain and Salmonella enterica serovar Infantis were isolated from the four positive flocks. Besides, Salmonella enterica serovar Javiana was isolated from flocks $B$ and $L$, and Salmonella enterica serovar $M$ bandaka was isolated from flock $L$. Eggs produced by flock $A$ and by flock $L$ were contaminated with $S$. Enteritidis and $S$. enterica rough strain. According to these results, Salmonella-infected flocks may produce contaminated eggs.

\section{INTRODUCTION}

Salmonella remains the main food borne bacterial diseases in human (Barrow, 2000), and many of the world outbreaks are related to food containing poultry products (Rodrigue et al., 1990; Cox, 1995). Besides, infected birds may develop the illness (Suzuki, 1994). Fowl are the specific host of Salmonella enterica serovars Pullorum and Gallinarum, which cause pullorum disease and fow I typhoid, respectively. Other serotypes with no specific host, such as Enteritidis and Typhimurium, may infect chickens and persist in the final poultry product, inducing or not clinical disease during rearing. Thus, the control of Salmonella in poultry flocks is crucial for poultry industry success.

Salmonella are introduced in poultry farms by several ways, including day-old infected chicks, domestic animals, human, equipment, water and feed (Barrow, 2000). Once the farm is contaminated, it is very difficult to eliminate Salmonella from the environment (Davies \& Wray, 1995b). Factors such as the presence of wild birds, rodents, domestic animals and insects, as well as intensive production systems and multiple age flocks keep Salmonella on farms, which compromise eradication methods (Berchieri Junior \& Barrow, 1995). 
Paratyphoid salmonellas are responsible for poor performance of breeders, decreased egg production by layers, infertility and mortality. Furthermore, there is restriction for commercialization and egg consumption also decreases (Barrow, 2000). Salmonella infections may cause systemic disease in young and adult chickens, associated with clinical symptoms and lesions in organs like liver, spleen, heart, and mostly the ceca (Suzuki, 1994; Barrow, 2000). In addition, with or without clinical disease, Salmonella shedding occurs and the laid egg becomes contaminated (Suzuki, 1994; Barrow, 2000).

Infected breeder flocks are responsible for vertical transmission. The eggs are contaminated either from the ovary tissue or on their passage through the cloaca (Nakamura et al., 1993). Vertical transmission of Salmonella was reported by Zancan et al. (2000), who found $44.45 \%$ of positive transport boxes, and horizontal transmission of Salmonella enterica serovar Enteritidis (SE) was demonstrated by Gast \& Holt (1999) and Soncini et al. (2000). They reported that birds free of bacteria in contact with inoculated birds became infected and excreted SE in the feces within the following 12 to 24 hours. The duration of fecal excretion is not easily defined. According to Gast \& Holt (1998), laying hens experimentally exposed to SE soon after birth may remain infected until maturity, producing contaminated eggs and eliminating the bacteria to the environment. Conversely, Berchieri Júnior et al. (2001) reported that chicks orally infected with SE at 7 days of age presented systemic infection, and the bacteria were isolated from liver and ceca for 10 weeks, but not after this period.

Since the 80 's, the number of human food borne salmonellosis has increased worldwide and has been mostly related to the consumption of poultry products (Rodrigue et al., 1990; Taunay et al., 1996). On the other hand, it was demonstrated that the food was prepared with raw egg contaminated by SE (Duguid \& North, 1991; Mishu et al., 1991; Cox, 1995; Barrow, 2000).

All control programs of infectious diseases are based on the knowledge of the routes of introduction and pathogen dissemination. In view of the lack of information about the epidemiology of avian salmonellosis in commercial poultry in Brazil, this work was carried out to investigate the presence of Salmonella in naturally infected flocks of commercial laying hens from new ly hatched chicks up to 76 weeks of age. The presence of Salmonella was also investigated in eggs laid by hens at 56 weeks of age.

\section{MATERIAL AND METHODS}

Twelve flocks of white laying hens were inspected prior the beginning of the experiment (Table 1). Salmonella was searched inside all transport boxes when one-day-old chicks arrived at different farms (100 chicks/ box). Four Salmonella-positive flocks and one negative flock were used in the experiment. Samples of feces were collected for bacteriological examination starting on the seventh day and at every four weeks thereafter, up to 52 weeks. Additional evaluations were performed in 500 eggs laid by hens with 52 weeks of age, and after molting in fecal samples from 76-week-old birds.

Experimental procedure was done according Wray and Davies (1994) recommendations.

\section{Sampling of transport boxes}

Samples were taken from the internal wall and bottom of the transport boxes using one large gauze swab per box, moistened in PBS pH 7.4. Five swabs were placed in a glass jar containing $100 \mathrm{~mL}$ selenite broth (CM 395) plus novobiocin (40mg/L) and incubated overnight at $42^{\circ} \mathrm{C}$. The broth was plated on brilliant green agar (Oxoid CM 263) and MacConkey agar (Oxoid CM 115) and plates were incubated overnight at $42^{\circ} \mathrm{C}$. Suspected colonies were inoculated

\begin{tabular}{ccc}
\hline Table 1 & $\begin{array}{r}\text { Isolation of Salmonella sp from } \\
\text { one-day-old birds. }\end{array}$ & transport boxes of \\
Flock & Number of birds & Serovar \\
\hline A* & 4,800 & Enteritidis \\
\hline B* & 2,000 & Enteritidis and R strain*** \\
\hline C & 8,000 & Negative \\
D & 3,500 & Negative \\
E & 7,000 & Negative \\
\hline F & 7,000 & Negative \\
G & 4,000 & Negative \\
H & 10,000 & Negative \\
I** & 2,000 & Negative \\
J & 7,000 & Negative \\
L* & 2,100 & Enteritidis \\
M* & 4,000 & Enteritidis \\
\hline
\end{tabular}

\footnotetext{
* Positive flocks used to carry on the research.

$* *$ Negative flock used to carry on the research.

$* * * \mathrm{R}$ : rough strain.
} 
in TSI agar (Oxoid CM 277) and lysine iron agar (CM 281), incubated overnight at 37으 $\mathrm{C}$ and confirmed using polyvalent sera against $\mathrm{O}$ and $\mathrm{H}$ Salmonella antigens (Probac). Complete identification and serotyping of the isolates were performed at the Adolfo Lutz Institute in São Paulo, Brazil.

\section{Feces}

Fresh samples of cecal feces were collected under the cages of the birds. Each sample corresponded to 200 birds up to 17 weeks and 100 birds afterwards. The samples were processed according to the procedure described above.

\section{Eggs}

Eggs were collected and placed in sterile trays, The trays were put in plastic bags and taken to the laboratory under refrigeration. Each egg was placed in a sterile glass jar and broken by agitation. The contents were mixed and the jars were incubated at $37^{\circ} \mathrm{C}$ for $24 \mathrm{~h}$. Bacteriological procedure was the same described above, except that Hektoen agar (Oxoid CM 409) was used instead MacConkey agar.

\section{RESULTS}

The presence of Salmonella was investigated in 614 boxes corresponding to 12 flocks of one-day-old birds. Salmonella Enteritidis was detected in four flocks (129 boxes). In one of these flocks, S. enterica rough strain ( $R$ strain) was also isolated (Table 1 ). Samples were collected from four positive flocks $(A, B, L$ and $M)$ and one negative flock (I) until the end of the experiment
(Table 2). The positive flocks showed the same result at the second sampling, but isolation varied afterwards. In flock A, Salmonella was isolated from fecal samples at $11,34,42$ and 76 weeks of age. Salmonella was isolated from fecal samples collected from flock $B$ at 4, 11 and 76 weeks of age. Flock L presented positive results for Salmonella isolation in all samplings from 17 to 52 weeks of age. Flock $L$ was not evaluated at 76 weeks of age because it was depopulated. Salmonella was not isolated from flock $M$ between 4 and 52 weeks of age, but it was detected at 76 weeks of age. Flock I presented negative results throughout the experimental period, even after molting. Several serovars of Salmonella were isolated (Table 3). S. Enteritidis, rough strain and $\mathrm{S}$. enterica serovar Infantis were isolated from fecal samples from the four positive flocks, S. enterica serovar Javiana was isolated from fecal samples from flocks $B$ and $L$, and $S$. enterica serovar $\mathrm{M}$ bandaka was isolated only from flock $\mathrm{L}$.

Salmonella was studied in 500 eggs from each flock (Table 4). SE and R strain were found in one egg from flock $A(0.2 \%)$ and $R$ strain was also isolated from 10 eggs from flock $L(2.0 \%)$.

\section{DISCUSSION}

Salmonella was detected in four transport boxes $(33.3 \%)$ from a total of 614 boxes with one-day-old laying hens. Similarly, Salmonella was found in $20 \%$ of the samples of meconium and fluff (Bhatia \& $M$ cnabb, 1980), 17\% of the samples taken from commercial hatchery residues (Bailey et al., 1994), $26 \%$ of the samples of transport boxes and egg shell (Cox et al., 1997) and $44.45 \%$ of transport boxes (Zancan et al., 2000).

Table 2 - Isolation of Salmonella sp from transport boxes and feces of laying hens.

\begin{tabular}{|c|c|c|c|c|c|c|c|c|c|c|c|c|c|c|c|c|}
\hline \multirow[t]{2}{*}{ FLOCK } & \multicolumn{14}{|c|}{ AGE (w eeks) } & \multirow[b]{2}{*}{52} & \multirow[b]{2}{*}{ 76(molt) } \\
\hline & 0(1day) & 1 & 4 & 8 & 11 & 14 & 17 & 20 & 25 & 30 & 34 & 38 & 42 & 48 & & \\
\hline$A$ & + & + & - & - & + & - & - & - & - & - & + & - & + & - & - & + \\
\hline$B$ & + & + & + & - & + & - & - & - & - & - & - & - & - & - & - & + \\
\hline $\mathrm{L}$ & + & + & - & - & - & - & + & + & - & + & + & + & + & + & + & NP \\
\hline M & + & + & - & - & - & - & - & - & - & - & - & - & - & - & - & + \\
\hline I & - & - & - & - & - & - & - & - & - & - & - & - & - & - & - & - \\
\hline
\end{tabular}

(+): Isolation of Salmonella.

$(-)$ : No isolation of Salmonella.

NP: not performed. 
Table 3 - Salmonella sp serovares isolated from transport boxes and feces of light white laying hen flocks.

\begin{tabular}{|c|c|c|c|c|}
\hline \multirow[b]{2}{*}{ AGE (w eeks) } & \multicolumn{4}{|c|}{ FLOCKS } \\
\hline & $\mathbf{A}$ & B & $\mathbf{L}$ & M \\
\hline 0 (1 day) & Enteritidis & Enteritidis, R strain* & Enteritidis & Enteritidis \\
\hline 1 & Enteritidis, R strain & Enteritidis, Infantis, R strain & Enteritidis, R. strain & Enteritidis, R. strain \\
\hline 4 & $-* *$ & Enteritidis & - & - \\
\hline 8 & - & - & - & - \\
\hline 11 & Enteritidis & Enteritidis & - & - \\
\hline 14 & - & - & - & - \\
\hline 17 & - & - & Infantis & - \\
\hline 20 & - & - & Enteritidis, Javiana, M bandaka, Infantis & - \\
\hline 25 & - & - & - & \\
\hline 30 & - & - & R strain & - \\
\hline 34 & Infantis & - & R strain & - \\
\hline 38 & - & - & Enteritidis, R strain & - \\
\hline 42 & Enteritidis, R strain & - & Enteritidis, R strain & - \\
\hline 48 & - & - & R strain & - \\
\hline 52 & - & - & Enteritidis, R strain & - \\
\hline 76 & Infantis, R strain & Javiana & - & Infantis \\
\hline
\end{tabular}

$* \mathrm{R}$ : rough strain.

$* *$ No isolation of Salmonella.

Table 4 - Serovar of Salmonella sp isolated from eggs produced by 52-week-old layers.

\begin{tabular}{lcccc} 
Flocks & Number of analyzed eggs & Number of positive eggs & Positive eggs (\%) & Serovars \\
\hline A & 500 & 1 & 0.2 & Enteritidis and *R strain \\
B & 500 & 0 & 2.0 & - \\
\hline L & 500 & 10 & - & R strain \\
M & 500 & 0 & - & - \\
I & 500 & 0 & - \\
\hline
\end{tabular}

*R strain: rough strain. 
The presence of Salmonella sp in transport boxes of day-old birds strongly suggests the occurrence of vertical transmission (Lister, 1988; Mc Ilroy \& M Mc Craken, 1990). Bacteria are present in chicks for a long period of time when they are exposed to Salmonella at the end of the hatchery period or during the first hours of life, and may be disseminated to other susceptible chicks in the same flock or other flocks (Gast \& Holt, 1998). Therefore, the first step to prevent Salmonella introduction in farms is to obtain Salmonellafree chicks, avoiding lateral transmission. Since there are many sources of Salmonella contamination in commercial poultry production, the negative results found in flock I cannot be attributed only to the introduction of non-infected chicks. How ever, the results suggest that obtaining Salmonella free-birds is the first step for preventing Salmonella on the farm.

Salmonella serotypes other than those isolated from the transport boxes were detected during rearing and production in the four positive flocks. Besides vertical transmission, Salmonella may be introduced in poultry farms by several ways, mainly by feed containing meal of animal origin (Berchieri Júnior et al., 1993). Rodents have great importance on the epidemiology of avian salmonellosis, because they maintain paratyphoid salmonellas such as serotypes Enteritidis and Typhimurium in the poultry houses (Davies \& Wray, 1995a). According to these authors, even after cleaning and disinfection, poultry houses are re-contaminated by infected resident rodents. Furthermore, the deficiency on the disinfecting process may contribute to the maintenance of Salmonella at farms (Davies \& Wray, 1995b). It should be also considered that light lines of birds are supposed to be resistant to Salmonella. In fact, the hens did not show signs of illness although they were infected and bacteria were shed for some time. Therefore, although natural and individual resistance of birds might be considered (Protais et al., 1996; DuchetSuchaux et al., 1997; Bumstead, 2000), it is necessary to remember that while commercial lines of chickens are homogeneous for production, there is not enough knowledge about their susceptibility to infection. Moreover, genes responsible for the resistance to systemic infection are not related to resistance to the colonization of the intestinal tract by Salmonella (Bumstead, 2000).

Several factors might be related to the non-isolation of Salmonella sp from fecal samples in flocks B and M during the first production cycle and the absence of infection in Flock I. Birds acquire natural resistance against enteric pathogens with the gradual development of the intestinal flora and the immune system (Suzuki, 1994; Gast, 1997). In addition, an appropriate cleaning and disinfection program associated with a good quality of living birds might decrease the risk of environmental contamination (Barrow, 1999).

Molting is a debilitating process used to extend the productive life of the birds. During molting, birds become more susceptible to infection by pathogens. In fact, flocks $A, B$ and $M$ were evaluated after molting (76 weeks-old) and were excreting Salmonella, similar to what was reported by Nakamura et al. (1994), Holt (1995), and Macri et al.(1997).

The percentage of contaminated eggs was 0.2 and $2.0 \%$ in Flocks $A$ and $L$, values in accordance to the values of 0.1 to $10.0 \%$ reported by Humphrey (1994). Although Salmonella was detected in few eggs, inadequate storage conditions and food prepared with raw eggs can be a serious threat to human health (Humphrey et al., 1989). Eggs may become contaminated by Salmonella in the ovary and oviduct (Thiagarajan et al., 1994; Keller et al., 1995; Miyamoto et al., 1997). Most of the times, however, contamination occurs in the cloaca during egg passage. It is well known that the number of Salmonellacontaminated eggs decreases, together with a decrease in fecal shedding.

M ost food-borne infections caused by Salmonella in humans were associated to food like mayonnaise, ice cream and frozen desserts, which are consumed without being cooked after raw egg is added. Provided that few Salmonella organisms are present on egg shells or egg contents, they multiply in a few minutes during storage at room temperature (Duguid \& North, 1991).

Similar to the results described by Zancan et al. (2000), SE was also predominant among the serotypes isolated from transport boxes of one-day-old chicks. This serotype was also frequently isolated from chicken feces after one week of age and was detected in eggs laid by flock $A$. SE has been associated to food-borne disease since the last century (Barrow, 1993). How ever, in the last decades, there was an increase in human cases, and most cases were associated to poultry products (Barrow, 2000). In the present work, SE was detected in chicks from flocks A from one-day old until the end of the trial, resulting in the production of contaminated eggs. Besides, SE intoxication also increased in Brazil in the last years (Taunay et al., 1996; Hofer et al, 1997) and thus, it is evident that more efficient control measures are needed.

Salmonella Infantis, also isolated from fecal samples from four flocks, was implicated in food 
borne human salmonellosis in Finland related to consumption of poultry meat (Nurmi \& Rantala, 1973). S. Infantis and S. M bandaka were isolated from eggs, from flies and other insects present in the chicken houses, and from swab samples taken from the environment (Jones et al., 1995; Kinde et al., 1996; Olsen \& Hammack, 2000). These two serotypes were also isolated from humans presenting symptoms of salmonellosis (Scheil et al., 1998; Dera-Tomaszewska \& Glosnicka, 1999). According to Hoszowski \& Wasyl (2001), domestic poultry is the main source of $\mathrm{S}$. $M$ bandaka infection for men.

Salmonella Javiana isolated from feces in Flocks B and $L$ had already been detected in domestic chickens by Adesiyun et al. (1998). It also causes gastroenteritis in human and was considered the sixth most incident serotype in 1996 by CDC, in USA. In Brazil, according to Tavechio et al. (1996) and Villa (2000), S.Infantis, S. $M$ bandaka and $\mathrm{S}$. Javiana are among the serotypes frequently isolated in samples from human, poultry and other animal sources, from the environment and from feed and feedstuffs.

In many occasions rough strains of Salmonella were isolated. The biochemical behavior was compatible with the profile of paratyphoid strain. Some evidence suggested they might be of the serovar Enteritidis, nevertheless, the impossibility of identifying them hinders any epidemiological analysis.

In the present experiment the presence and the persistence of Salmonella were shown in laying hen flocks since their arrival until the end of the production period. These results demonstrated that improvements are needed in Salmonella control program because those currently adopted have not been able to prevent the introduction and dissemination of salmonellas on poultry farms, as well as egg contamination.

\section{REFERENCES}

Adesiyun AA, Seepersadsingh N, Inder L, Caesar K. Some bacterial enteropathogens in wildlife and racing pigeons from Trinidad. Journal Wildlife Diseases 1998; 34:73-80.

Bailey JS, Cox NA, Berrang ME. Hatchery-acquired Salmonella in broiler chicks. Poultry Science 1994; 73:1153-7.

Barrow PA. A Salmonella control-past, present and future. Avian Pathology 1993; 22:651-69.

Barrow PA. Salmonella em avicultura - problemas e novas idéias sobre possibilidades de Controle. Revista Brasileira de Ciência Avícola 1999; 1:9-16.

Barrow PA. The paratyphoid salmonellae. Review Science Technology
Office International Epizootic 2000; 19:351-75.

Berchieri Júnior A, Barrow PA. Patologia e métodos de diagnósticos de SE em aves. In: Conferência Apinco de Ciência e Tecnologia Avícolas; 1995; Curitiba, PR. Brasil. p. 1-5.

Berchieri Júnior A, W igley P, Page K, M urphy CK, Barrow PA. Further studies on vertical transmission and persistence of Salmonella enterica serovar Enteritidis phage type 4 in chickens. Avian Pathology 2001; 30:297-310.

Berchieri Júnior A, Fernandes AS, Irino K, Quintana JL, Santos AJ. Salmonella in poultry feeds in Brazil. Revista de M icrobiologia 1993; 24:22-5.

Bhatia TRS, M cnabb GD. Dissemination of Salmonella in broiler chick operations. Avian Diseases 1980; 24: 616-24.

Bumstead N. Mecanismos genéticos de resistência a doenças. In: Conferência Apinco de Ciência e Tecnologia Avícolas; 2000; Campinas, SP. Brasil. p. 25-30.

Cox JM. Salmonella Enteritidis: the egg and I. Australian Veterinary Journal 1995; 72 (3): 108-15.

Cox NA, Bailey JS, Berrang ME. Diminishing incidence and level of Salmonella in a commercial broiler hatcheries. Journal of Applied Poultry Research 1997; 6:90-3.

Davies RH, Wray C. Mice as carriers of Salmonella enteritidis on persistently infected poultry units. The Veterinary Record 1995a; 137:337-41.

Davies RH, Wray C. Observations on disinfection regimens used on Salmonella enteritidis infected poultry units. Poultry Science $1995 \mathrm{~b}$; 74:638-47.

Dera-Tomaszewska B, Glosnicka R. Salmonella serovars determined in the National Salmonella Center between 1995 and 1997. Przel Epidemiology 1999; 53:365-9.

Duchet-Suchaux M , M ompart F, Berthelot F, Beaumont C, Léchopier $P$, Pardon P. Differences in frequency, level, and duration of cecal carriage between four outbreed chicken lines infected orally with Salmonella enteritidis. Avian Diseases 1997; 41:559-67.

Duguid JP, North AE. Eggs and salmonella food-poisoning: an evaluation. Journal of M edical Microbiology 1991; 34:65-72.

Gast RK. Salmonella Infections. In: Calnek BW, Barnes HJ, Beard CW, MCDougald LR, Saif YM, editors. Diseases of Poultry. Ames: lowa State University Press; 1997. p. 81-129.

Gast RK, Holt PS. Persistence of Salmonella enteritidis from one day of age until maturity in experimentally infected layer chickens. Poultry Science 1998; 77:1759-62.

Gast RK, Holt PS. Experimental horizontal transmission of Salmonella enteritidis strains (phage types 4, 8 and 13 a) in chicks. Avian Diseases 1999; 43:774-8.

Hofer E, Silva Filho SJ, Reis EM FR. Prevalência de sorovares de Salmonella isolados de aves no Brasil. Pesquisa Veterinária Brasileira 
$1997 ; 17: 55-62$.

Holt PS. Horizontal transmission of Salmonella enteritidis in molted and unmolted laying chickens. Avian Diseases 1995; 39:239-49.

Hoszowski A, Wasyl D. Typing of Salmonella enterica subsp. Enterica serovar M bandaka isolates. Veterinary Microbiology 2001; 80: 139-48.

Humphrey TJ. Contamination of eggs with potential human pathogens. In: Board RG, Fuller R, editors. M icrobiology of the avian egg, Londres. Chapman \& Hall; 1994. p.93-116.

Humphrey TJ, Baskerville A, M awer S, Rowe B, Hooper S. Salmonella enteritidis phage type 4 from the contents of intact eggs: a study involving naturally infected hens. Epidemiology and Infection 1989; 103: 415-23.

Jones FT, Rives DV, Carey JB. Salmonella contamination in commercial egg production facility. Poultry Science 1995; 74:753-7.

Keller LH, Benson CE, Kroteck Eckroade RJ. Salmonella enteritidis colonization of the productive tract and forming and freshly laid eggs of chickens. Infection and Immunity 1995; 63: 2443-9.

Kinde $H$, Read DH, Ardans A, Breirmeyer RE, Villoughby D, Little H, Kerr D, Gireesh R. Nagajara KV. Sewage effluent: likely source of Salmonella enteritidis. Avian Diseases 1996; 40:672-6.

Lister SA. Salmonella enteritidis infection in broilers and broiler breeders. Veterinary Record 1988; 123(13):350.

Macri NP, Porter RE, Holt PS. The effects of induced molting on the severity of acute intestinal inflammation caused by Salmonella enteritidis. Avian Diseases 1997; 41:117-24.

Mc Iroy SG, Mc Craken RM. The current status of the Salmonella enteritidis control program in the United Kingdom. In: Annual Meeting of the UK Animal Health Association, 1990, London. England. p.450-62.

Mishu B, Griffin PM, Tauxe RV, Cameron DN, Hutcheson RH, Schaffner W. Salmonella enteritidis gastroenteritis transmitted by intact chicken eggs. Annals of the International Medicine 1991; 115:190-4.

Miyamoto T, Baba E, Tanaka T, Sasa K, Fukata T, Arakawa A. Salmonella enteritidis contamination of eggs from hens inoculated by vaginal, cloacal, and intravenous routes. Avian Diseases 1997; 41:296-303.

Nakamura M, Nagamine N, Norimatsu M, Suzuli S, Onishi K, Kigima $M$, Tamura $Y$, Sato $S$. The ability of Salmonella enteritidis isolated chicks imported from England to cause transovarian infection. Journal of Veterinary M edical Science 1993; 55:135-6.

Nakamura M, Nagamine N, Takahashi T, Suzuki S, Kijima M , Tamura $Y$, Sato S. Horizontal transmission of Salmonella enteritidis and effect of stress on shedding in laying hens. Avian Diseases 1994; $38: 282-8$.

Nurmi E, Rantala M. New aspects of Salmonella infection in broiler production. Nature 1973; 241:210-11.

Olsen AR, Hammack TS. Isolation of Salmonella spp from the housefly, M usca domestica L., and the dump fly, Hidrotaea aenescens (Wiedemann) (Diptera: Muscidae), at caged-layer houses. Journal of Food Protection 2000; 63958-60.

Protais J, Colin P, Beaumont C, Guillot JF, Lantier F, Pardon P, Bennejean $G$. Line differences in resistence to Salmonella enteritidis PT4 infection. Britsh Poultry Science 1996; 37:329-39.

Rodrigue DC, Tauxe RV, Rowe B. International increase in Salmonella enteritidis: A new pandemic? Epidemiology and Infection 1990; 105:21-7.

Scheil W, Cameron S, Dalton C, Murray C, Vilson D. A South Australian Salmonella Mbandaka outbreak investigation using database to select controls. Australian Journal of Public Health 1998; 22:536-9.

Soncini RA, Mores MAS, Costa JLA. Transmissão horizontal de Salmonella Enteritidis em pintos de um dia. Revista Brasileira de Ciência Avícola 2000; 2:94.

Suzuki S. Pathogenicity of Salmonella enteritidis in poultry. International Journal of Food M icrobiology 1994; 21:89-105.

Taunay AE, Fernandes SA, Tavechio AT, Neves BC, Dias AMG, Irino $K$. The role of Public Health Laboratory in the problem of Salmonellosis in São Paulo, Brasil. Revista do Instituto de Medicina Tropical 1996; 38:119-27.

Tavechio AT, Fernandes AS, Neves BC, Dias AM G, Irino K. Changing patterns of Salmonella serovares: increase of Salmonella Enteritidis in São Paulo, Brazil. Revista do Instituto de Medicina Tropical 1996; 38:315-22.

Thiagarajan D, Saeed AM, Asem EK. Mechanism of transovarian transmission of Salmonella enteritidis in laying hens. Poultry Science 1994; 73:89-98.

Villa M FG. Salmoneloses aviárias no Brasil - Avaliação epidemiológica. [Dissertação]. Seropédica (RJ): Universidade Federal Rural do Rio de Janeiro; 2000.

Wray C, Davies RH. Guideline on detection and monitoring of Salmonella infected poultry flocks with particular reference to Salmonella Enteritidis. Graz: WHO, 1994. p.8-17.

Zancan FT, Berchieri Júnior A, Fernandes AS, Gama NM SQ. Salmonella spp investigation in transport boxes of day-old birds. Brazilian Journal of Microbiology 2000; 31:230-2. 